\title{
Does mammographic screening and a negative result affect attitudes towards future breast screening?
}

\author{
C H C Drossaert, H Boer, E R Seydel
}

\begin{abstract}
Objectives-To investigate the impact of an experience of a benign mammographic result on intention to seek medical help immediately in the case of breast abnormalities, and on intentions and thoughts about future participation in screening. Setting-The Dutch Breast Cancer Screening Programme for women aged 50-69.

Methods-Subjects were women who were invited for an initial breast examination: 223 women filled out a questionnaire about 10 days before and about 6 weeks after their initial breast examination. To be able to control for possible test effects, another group of 293 women filled out a questionnaire only after mammography. Changes in thoughts and intentions were examined.
\end{abstract}

Results-Most women were very satisfied with the course of their initial breast examination, although pain or discomfort was often mentioned. No clues to suggest false reassurance were found: more than $\mathbf{9 9 \%}$ of the women would consider the possibility of breast cancer if they felt a lump in one of their breasts. In such a situation, most women intended to seek medical help within a week. These variables were not influenced by the experience of mammography with a benign result. In general, women were very positive about (repeat) participation, both before and after screening. After screening, the average woman perceived fewer costs in participating, and perceived her own ability to engage in future screening as higher. However, the experience of pain and anxiety during the initial screening did lead to reverse effects. Women who were less satisfied about their treatment by the staff were more likely to change their intentions to reparticipate in a negative way.

Conclusions-As, in general, women became more positive about regular participation after they had attended breast cancer screening, efforts to improve first round attendance must be continued. At the same time, the screening organisations must continue to prioritise the high level of client friendliness throughout the screening. No evidence for detrimental effects of screening through false reassurance among participants was found. (F Med Screen 2001;8:204-212)
Keywords: breast cancer; screening; experiences; beliefs; participation

Based on the promising results of experimental studies with population screening for breast cancer in the United States, ${ }^{1}$ Sweden, ${ }^{23}$ and The Netherlands ${ }^{45}$ a nationwide breast cancer screening programme has been gradually implemented in The Netherlands since the early 1990s. In the Dutch screening programme, all women aged 50 to 69 are invited for a free mammography every 2 years. Most women participating in this screening programme receive a negative screening resultthat is, they learn every 2 years that no abnormalities were found. In this study we examined the interpretation by the women of a negative screening result, and to what extent breast screening with a normal result affected women's intentions towards (a) seeking medical help promptly in the case of breast abnormalities and $(b)$ repeat participation in subsequent screening rounds.

IMPACT OF SCREENING ON INTENTION TO SEEK HELP IN THE CASE OF FUTURE BREAST

ABNORMALITIES

It has been suggested by various authors ${ }^{6-8}$ that screening might cause false reassurance among those women who participate in the programme and receive negative screening results. False reassurance describes the feelings of security associated with receiving a negative breast screening result: women might think (mistakenly) that they are "protected" against getting breast cancer, which might lead to a more casual attitude in those particular women to remaining alert to the warning signs of breast cancer. False reassurance can be detrimental, because it might cause delay in diagnosis and treatment of tumours that develop in the period between two screening rounds. Such so called "interval tumours" -breast cancers diagnosed between two screening rounds-are common in population based breast screening. It is expected that the ratio between screen detected tumours and interval tumours is about 2-3:1 for women older than 50 years. ${ }^{29}{ }^{10}$ Because of the high incidence of interval tumours, it is important that women who participate in regular breast screening remain alert to the symptoms of breast cancer, and that they seek medical attention immediately for any suspicious findings. It is important that women understand the relative nature of the screening result, and that breast cancer might occur despite the negative result. To our knowledge, a woman's 
interpretation of a negative breast screening result, and the impact of screening on intention to seek help, have not been investigated. In this study we examined whether a negative screening result was well interpreted and whether false reassurance occurred.

IMPACT OF A NEGATIVE SCREENING RESULT ON THOUGHTS AND ATTITUDES ABOUT FUTURE PARTICIPATION

Among other factors, participation is an important determinant for the success of the breast screening programme. In this respect, it is important that women not only attend the initial screening, but also all subsequent screening rounds. Various studies have shown that participation rates, although high in the first round, often drop during the course of the screening programme. ${ }^{11-13}$ Although relatively little research has been undertaken to establish factors that improve or inhibit long term participation in breast screening programmes, ${ }^{14-20}$ several studies have investigated factors that improve or impede first round participation in such programmes. ${ }^{21-23}$ Alongside sociodemographic factors such as age, marital status, and educational background, the attitudes and opinions underlying a woman's decision to participate in screening have been studied. Insight into these so called "cognitive determinants" is important as it provides a useful basis for health promotion activities.

Various psychological models - such as the health belief model, ${ }^{24}$ the theory of planned behaviour, ${ }^{25} 26$ and protection motivation theory ${ }^{27}$ - provide various cognitive determinants underlying the decision to engage in health behaviour. These theories, or combinations of them, have been used to examine numerous health behaviours including nonparticipation in breast cancer screening. ${ }^{15} 1629-33$

One major determinant is the perceived threat of the disease, including beliefs about susceptibility and severity-for example, a women is more likely to participate in breast cancer screening if she considers herself more susceptible to breast cancer and perceives breast cancer as a more severe disease. Another cognitive determinant of participation is the balance between costs and benefits of participation. A woman is more likely to participate in breast cancer screening if she associates fewer costs (radiation, worries, and pain) and more benefits (reassurance, early detection) from it. Subjective norm refers to a woman's perception of expectations of other relevant people about her participation in breast screening and is another factor that might influence a woman's decision to participate in screening. A final cognitive determinant of participation in screening is self efficacy, defined as a woman's belief in her ability to actually participate in breast screening.

In our study, these cognitive determinants were measured both before and after screening to gain insight into the effects of a screening experience with a negative result. We expected that the cognitive determinants of repeat participation would be influenced by the expe- rience itself and by a negative screening result. For instance, a negative screening result might influence a woman's ideas about her susceptibility to breast cancer. Moreover, the actual experience of undergoing a mammography (which is inseparably connected to the screening result) is also likely to influence a woman's ideas about her reparticipation in future rounds. For instance, negative experiences during the mammography (anxiety or pain) might result in lower expectations of self efficacy. Both diminished expectations of self efficacy and diminished susceptibility might eventually reduce the intention to reparticipate in future screening rounds.

In summary, our study was conducted to examine the effect of a screening experience with a negative result on women's beliefs and intentions toward future participation in the screening programme, and on women's intentions to seek help in the case of breast abnormalities.

\section{Subjects and methods}

\section{SETTING}

Our study took place in a rural area in the east of The Netherlands, where the first round of the Dutch national screening programme was performed. The breast examinations were performed in semimobile screening units. Names and addresses of all women aged 50 to 69 were provided by the population registers of the local councils. A regional screening organisation invited every woman by letter for a free mammogram, giving a fixed appointment which could be changed on request. An information leaflet was enclosed with the invitation, giving general information about breast cancer, the benefits of early detection and about the breast screening programme, and more detailed information about the specific procedures of the breast examination. Every woman received the outcome of the screening by post within 2 weeks of the mammogram.

\section{DESIGN AND SUBJECTS}

During a 3 month period in which women were invited for their initial mammogram, 20\% were selected at random to participate in the study. To measure the effects of the screening, two measurements were taken: about 10 days before the scheduled mammography and about 6 weeks after it. Written questionnaires were used both before and after mammography. To ensure that the questionnaire was actually filled out before the mammogram, the questionnaires before mammography were collected at the women's homes.

Because women were asked to fill out two similar questionnaires in a short period, the danger of a testing effect existed. To control for possible testing effects, no questionnaire before mammography was sent to part of the sample (the after only group). Women were randomly assigned to either the before+after group or to the after only group. The response data are presented in table 1 . In the before+after group, 247 women (55\%) completed both questionnaires; in the after only group 327 women $(75 \%)$ completed the questionnaire. Women 
Table 1 Response to questionnaires before and after mammography

\begin{tabular}{|c|c|c|c|c|c|c|}
\hline \multirow[b]{2}{*}{ Group } & \multicolumn{3}{|c|}{ Before } & \multicolumn{3}{|l|}{ After } \\
\hline & Sent & Returned & $\%$ & Sent & Returned & $\%$ \\
\hline Before+after & 451 & 321 & 71 & 321 & 247 & 77 \\
\hline After only & - & - & - & 435 & 327 & 75 \\
\hline
\end{tabular}

who were under treatment for breast cancer (before+after group $\mathrm{n}=6$ : after only group $n=12$ ) were excluded from analyses. Because the study was aimed at examining the effect of participating in screening with a negative (benign) result, women who had not participated in the initial screening (before+after group $\mathrm{n}=11$ : after only group $\mathrm{n}=20$ ) and women who had received a positive (suspect) screening result (before+after group $\mathrm{n}=1$ : after only group $n=2$ ) were also excluded from further analysis. This left a total of 522 subjects for analysis (before+after group $n=229$ : after only group $n=293$ ).

QUESTIONNAIRES

The questionnaires contained questions on the following subjects:

\section{Personal characteristics and use of information leaflet}

Personal characteristics and use of the health education leaflet were measured only once; before mammography in the before+after group, and after screening in the after only group. Demographic characteristics included: age, education, employment, and marital status. Each woman was asked about her experiences with breast cancer: if she had ever had a benign breast abnormality; and whether she knew someone close to her who had been treated for breast cancer. To establish family history of breast cancer, women were asked to indicate whether their mother or sister had ever been treated for breast cancer. Use of the information leaflet was measured by asking women the extent to which they had read the enclosed information leaflet (not at all, glanced at it, read some parts, read it completely).

Cognitive determinants of repeat participation Intention to reparticipate was measured for the next screening round and all subsequent screening rounds. Answering options varied from "strongly intend to participate" (2) to "strongly intend not to participate" (-2). Because the items were highly intercorrelated $(r=0.80)$ mean scores were computed. Benefits of participation in breast screening were measured with a three item scale $(\alpha=0.67)$. An example is: "If I would participate in the screening and abnormalities were found, the possibility of breast conserving treatment would be higher.....fully disagree (1) to fully agree (5)". Costs (women's perceptions of physical and psychological costs of participating in breast screening) were measured with a four item scale $(\alpha=0.60)$. For example: "Having a mammogram, takes a lot of time"... fully disagree (1) to fully agree (5)'. Susceptibility was measured with a four item scale $(\alpha=0.77)$.
An example of a susceptibility item is: "The chance that I will develop breast cancer in my lifetime is... very small (1) to very high (5)". Subjective norms were measured based on the work of Ajzen and Fishbein ${ }^{25}$ and were composed of two parts: normative beliefs and motivations to comply. An example of a normative belief question is: "My (referent person) thinks that I certainly ... should (2) to should not (-2) participate". An example of a motivation to comply question is: "When it comes to early detection behaviour I . . . do strongly (3) to do not (0) ... comply with the opinion of my (referent person)". Normative beliefs and motivations to comply were measured relative to six referents-namely: partner, children, family/friends, peers, family doctor, and the organisation sending the mammography invitations. The subjective norm was computed by taking the mean of the products of normative beliefs and motivation to comply $(\alpha=0.79)$. Self efficacy was measured with seven items about the difficulties that women expected with several practical and psychological aspects of screening participation $(\alpha=0.71)$. For example: "Getting to the screening unit is very difficult (1) to not difficult at all (4)". All the above mentioned cognitive determinants were measured in the questionnaire both before and after mammography.

Satisfaction and experiences with mammography The questionnaire after screening included some questions about women's experiences during the mammography. General satisfaction was measured with two questions: firstly, women were asked to indicate how satisfied they were in general with the course of the breast examination (ranging from very unsatisfied (1) to very satisfied (4)) and secondly, women were asked to what extent had the breast examination been as they expectated (ranging from worse than expected $(-2)$ to better than expected (2)).

A few questions dealt with women's appreciation of the organisational aspects of the screening experience-namely: travel times, waiting times, and appreciation of privacy within the unit. Perceived treatment by staff was measured with an eight item scale $(\alpha=0.80)$. Women were asked to mark at four point scales the extent to which they found the radiology assistants kind, comforting, interested, hurried, and impersonal, and whether the staff were skilled, whether they took enough time, and whether they provided enough information. Anxiety provoked by the mammography was measured relative to three periods: before the examination, during the examination, and in the period between the examination and the result of the mammogram. For each period, women were asked to mark on a four point scale the extent to which they felt tense and anxious. Also, women were asked to mark how much they had worried about the test results. As the seven questions were highly intercorrelated, the items were summarised into one mammography provoked anxiety scale $(\alpha=0.94)$. Pain was measured by 
Table 2 Personal characteristics, experiences with breast cancer, and use of information leaflet $(n=522)$

\begin{tabular}{ll}
\hline Age (mean) & 59.0 \\
Marital state (\%): & 84 \\
$\quad$ Married & 16 \\
$\quad$ Single, divorced, or widowed & \\
Employment (\%): & 85 \\
$\quad$ Unemployed & 12 \\
$\quad$ Part time job & 3 \\
$\quad$ Full time job & 74 \\
Education (\%): & 21 \\
$\quad$ low & 5 \\
$\quad$ Medium & \\
$\quad$ High & 11 \\
Family history of breast cancer (\%): & 12 \\
$\quad$ Yes & \\
Ever had a (benign) breast abnormality (\%): & \\
$\quad$ Yes & 62 \\
Breast cancer in someone close (\%): & \\
$\quad$ Yes & 54 \\
$\quad$ Has read leaflet completely (\%): & \\
$\quad$ Yes &
\end{tabular}

asking women to indicate the amount of experienced pain on a four point scale, ranging from not painful (1) to very painful (4).

Knowledge about interpretation of the screening result and intention to seek help

Both knowledge and intention to seek help were measured twice, before and after mammography. Knowledge about the interpretation of the screening result was measured with three true or false statements. These statements were: "If an abnormality is found on the mammogram, this always means that you have breast cancer", "If you participate in the screening programme, you cannot get breast cancer anymore", and "Participation in the screening programme makes breast self examination no longer necessary". To measure intention to seek help, the following scenario was presented to the women: "Imagine, 2 months from now, that you are taking a shower. While washing yourself you suddenly discover a small, painless lump in your left breast . . .. The scenario was followed by two questions. Women were asked to indicate on a five point scale, ranging from certainly not $(-2)$ to certainly (2), the extent to which they may think the lump could be breast cancer. They were also asked how long they would wait before contacting their general practitioner (GP) with the symptom. Answering options varied from "would contact GP within one week" (1) to "would wait longer than 6 months" (6).

STATISTICAL ANALYSIS

All analyses were performed with SPSS-PC+. All tests were two tailed and $\alpha$ s were set on 0.05. The effects of screening and screening result on intention to seek help and on determinants of repeat participation were examined by comparing scores after with before mammography, by multivariate and univariate analyses of variance (ANOVA). Before this, we checked whether the scores after screening of the before+after group differed significantly from the scores after mammography of the after only group, to examine whether testing had had an effect. Where no significant effects of testing were established, differences within subjects
Table 3 Aspects of screening experience turning out to be better or worse than expected

\begin{tabular}{ll}
\hline & $n(\%)$ \\
\hline Better than expected: & $33(41)$ \\
Pain & $30(38)$ \\
Treatment by staff, and atmosphere & $13(16)$ \\
Rapid & $4(5)$ \\
Screening result & $80(100)$ \\
Total & $19(73)$ \\
Worse than expected: & $2(8)$ \\
Pain, or duration of pain & $2(8)$ \\
Long waiting time & $1(4)$ \\
Extra mammography necessary & $1(4)$ \\
Laboratory assistant did not talk & $1(4)$ \\
Long distance to unit & $26(100)$ \\
There was no physical examination & \\
Total & \\
\hline
\end{tabular}

between before and after mammography in the before+after group were examined. Where significant testing effects appeared, the scores of the after only group were compared with the scores before mammography of the before+after group (between subjects design).

\section{Results}

DESCRIPTIVE RESULTS

Personal background variables, experiences with breast cancer, and use of health education

Table 2 shows that most of the women in the study were married, unemployed, and less well educated. Most women knew someone in their social environment who had been treated for breast cancer. About $11 \%$ reported to have a family history of breast cancer (mother or sister). Only $54 \%$ of the respondents indicated that they had read the enclosed information leaflet completely. Table 2 shows that no significant differences were found between the before+after group and the after only group, indicating that the randomisation had been successful.

\section{Satisfaction and experiences with the first} mammography

In general, women were satisfied with their first breast examination: $85 \%$ indicated that they were very satisfied; $13 \%$ that they were rather satisfied; only $5 \%$ considered the examination to be worse than expected; nearly $75 \%$ considered it to be better than expected. Using open ended questions, women were asked what turned out to be better or worse than expected. Many women wrote nothing, everything, or the examination. The more concrete answers are summarised in table 3. One remarkable finding was that pain was the most frequent answer on both questions. Obviously, many women had expected the examination to be painful. Another notable finding was that some women indicated that the pain had lasted (for a long time) after the breast examination.

Table 4 summarises the answers to the questions on different aspects of the mammography. The figures from table 4 underline the above finding that, in general, women were satisfied with the initial screening round. The screening unit offered enough privacy and was placed within easy reach of nearly all women. The waiting times were acceptable. Women were very positive about the treatment by the radiology assistants and for most women the 
Table 4 Evaluation of different aspects of the first mammography $(n=522)$

\begin{tabular}{|c|c|}
\hline \multicolumn{2}{|c|}{ Required time to get to the unit ( $\min , \%)$ : } \\
\hline$<15$ & 71 \\
\hline $15-30$ & 24 \\
\hline $30-60$ & 5 \\
\hline$>60$ & - \\
\hline \multicolumn{2}{|l|}{ Means of transport (\%): } \\
\hline On foot & 3 \\
\hline By bicycle & 61 \\
\hline By car & 34 \\
\hline By public transport or taxi & 3 \\
\hline \multicolumn{2}{|l|}{ Waiting time (min, \%): } \\
\hline No waiting time & 13 \\
\hline$<15$ & 78 \\
\hline $15-30$ & 8 \\
\hline$>30$ & 1 \\
\hline \multicolumn{2}{|l|}{ Privacy within unit $(\%)$ : } \\
\hline Too little privacy & 1 \\
\hline Little privacy & 2 \\
\hline Enough privacy & 97 \\
\hline \multicolumn{2}{|l|}{ Pain $(\%)$ : } \\
\hline Not painful & 39 \\
\hline A little painful & 47 \\
\hline Rather painful & 11 \\
\hline Very painful & 3 \\
\hline \multicolumn{2}{|l|}{ Treatment by staff: } \\
\hline Eight item scale $(\min =1, \max =4)$ & 3.6 \\
\hline \multicolumn{2}{|l|}{ Anxiety caused by mammography: } \\
\hline Seven item scale $(\min =1, \max =4)$ & 1.6 \\
\hline
\end{tabular}

screening experience had not caused too much anxiety. However, 40 women ( $8 \%$ ) had anxiety scores of 2.5 or higher, which indicate moderate to high levels of anxiety. Over half of the respondents $(61 \%)$ considered the mammogram to be at least a little painful. Considerable to severe pain was mentioned by $14 \%$ of respondents. There were no significant differences in the experiences of the initial mammography between the before+after group and the after only group, indicating that the baseline measurement had not influenced the breast screening experience.

Knowledge about interpretation of the screening result

The answers on knowledge about interpretation of the result before and after screening are presented in table 5 and indicate that knowledge was very high. $\chi^{2}$ Tests showed that there were no significant differences between the answers after screening of the before+after and after only groups. Nor were there any significant differences between the scores before and after mammography. This indicates that the screening experience had not affected women's knowledge about the interpretation of the result.
EFFECTS OF THE EXPERIENCE OF MAMMOGRAPHY WITH NORMAL BENIGN RESULTS

Effects on intention to seek help in the case of breast abnormalities

The mean scores on the two items on intention to seek help are presented in table 6 . The table shows that most women would seriously consider the possibility of breast cancer if they discovered a breast lump in the near future. Both before and after the screening, less than $1 \%$ of the women indicated that a breast lump would definitely not be breast cancer. Most women $(>75 \%)$ would visit their GP within less than 1 week. Less than $4 \%$ would wait more than 1 month, less than $1 \%$ would wait longer than 2 months. The screening experience with a favourable result did not have any effects on these findings: even when women were recently reassured by a negative mammogram, they intended to seek medical help immediately if they discovered a breast lump in the near future.

Effects on cognitive determinants towards repeat participation

From the mean scores in table 7, it can be concluded that women in general were very positive about repeat participation: both before and after the first breast examination, women strongly intended to reparticipate in future screening rounds. In general, women felt susceptible to breast cancer, connected more benefits than costs to participating in the breast screening programme, were encouraged by their social environment to participate in the screening programme, and did not consider participation to be too difficult.

A significant overall effect of screening was established in the cognitive determinants of repeat participation $\left(\mathrm{F}_{\text {multiv }}(7,469)=3.5\right.$, $\mathrm{p}<0.001)$. Inspection of univariate tests showed that the overall difference was mainly caused by subjective norms. Women who had filled out a questionnaire before screening felt more strongly encouraged by their social environment in the questionnaire after screening than women who had not filled out the first questionnaire. The screening experience lead to a significant change in ideas about costs and self efficacy: after the first breast examination women linked fewer costs to undergoing a breast examination and considered future participation in the breast screening programme to be less difficult.

Table 5 Knowledge (\%) about interpretation of the screening result

\begin{tabular}{|c|c|c|c|c|c|c|}
\hline & \multicolumn{3}{|c|}{ Before screening $(n=224)$} & \multicolumn{3}{|c|}{ After screening $(n=522)$} \\
\hline & $\begin{array}{l}\text { Incorrect } \\
\text { answer }\end{array}$ & $\begin{array}{l}\text { Correct } \\
\text { answer }\end{array}$ & $\begin{array}{l}\text { Did not } \\
\text { know }\end{array}$ & $\begin{array}{l}\text { Incorrect } \\
\text { answer }\end{array}$ & $\begin{array}{l}\text { Correct } \\
\text { answer }^{\star}\end{array}$ & $\begin{array}{l}\text { Did not } \\
\text { know }\end{array}$ \\
\hline $\begin{array}{l}\text { If an abnormality is found on the mammogram, } \\
\text { this always means that you have breast cancer }\end{array}$ & 4 & 81 & 15 & 4 & 78 & 19 \\
\hline $\begin{array}{l}\text { Participation in the screening programme makes } \\
\text { breast self examination no longer necessary }\end{array}$ & 3 & 89 & 8 & 3 & 94 & 3 \\
\hline $\begin{array}{l}\text { If you participate in the screening programme, you } \\
\text { cannot get breast cancer anymore }\end{array}$ & 1 & 92 & 7 & 1 & 94 & 5 \\
\hline
\end{tabular}

*Answering options were true, false, and don't know. For all three statements the correct answer was false. 
Table 6 Effects of favourable screening result on intentions to seek help in the case of breast abnormalities

\begin{tabular}{|c|c|c|c|c|c|}
\hline \multirow[b]{2}{*}{$\begin{array}{l}\text { Imagine somewhere in the near future you } \\
\text { discover a small painless lump in your breast }\end{array}$} & \multicolumn{3}{|c|}{ Mean scores of questionnaire } & \multicolumn{2}{|l|}{ Test for effect } \\
\hline & $\begin{array}{l}\text { Before } \\
\text { mammography } \\
\text { (before+after } \\
\text { group) }\end{array}$ & $\begin{array}{l}\text { After } \\
\text { mammography } \\
\text { (before+after } \\
\text { group) }\end{array}$ & $\begin{array}{l}\text { After } \\
\text { mammography } \\
\text { (after only } \\
\text { group) }\end{array}$ & $\begin{array}{l}\text { Effect of } \\
\text { testing }\end{array}$ & $\begin{array}{l}\text { Effect of } \\
\text { screeningt }\end{array}$ \\
\hline $\begin{array}{l}\text { Would you think this may be cancer? } \\
(-2=\text { definitely not } \ldots 2=\text { definitely })\end{array}$ & 0.5 & 0.6 & 0.7 & NS & NS \\
\hline \multirow{2}{*}{$\begin{array}{l}\text { How long (weeks) would you wait before } \\
\text { contacting your GP? }(1=\leqslant 1 \text { week } . . \\
6=\geqslant 6 \text { months) }\end{array}$} & 1.3 & 1.2 & 1.3 & NS & NS \\
\hline & & & & $\begin{array}{l}F_{(2,449)}=0.7 \\
\mathrm{NS}\end{array}$ & $\begin{array}{l}F_{(2,174)}=1.0 \\
\mathrm{NS}\end{array}$ \\
\hline
\end{tabular}

^MANOVA (between subjects design) was used to compare the scores after mammography of the before+after group and the after only group.

†MANOVA (within subjects design for repeated measures) was used to compare the scores after mammography with the scores before mammography of the before+after group.

Influence of specific experiences on determinants of repeat participation

From the previous results it can be concluded that before, as well as after, the first breast screening experience, women were on average very positive about reparticipation. Moreover it was found that, although most women were very positive about the course of their initial breast examination, a few reported explicitly negative experiences such as pain or anxiety during the screening. The correlation coefficients between the specific experiences during initial mammography and the cognitive determinants of repeat participation, measured in the two questionnaires are presented in table 8 .

It can be read from table 8 that most experiences during the first mammography were only weakly correlated with cognitive determinants of repeat participation expressed in the second questionnaire. Women's intention to reparticipate in future screening was significantly stronger as they thought they had been better treated by the staff, and experienced less pain during the initial breast examination. Experienced pain and anxiety were moderately correlated with perceived costs and to expectations of self efficacy. A notable finding from table 8 is that some experiences of mammograms were significantly correlated with the cognitive determinants expressed before the screening.

To examine the impact of experiences on intention to reparticipate, a partial correlation analysis was performed. In this analysis, the correlation was examined between intention as indicated in the second questionnaire and specific experiences, while including intention as indicated in the first questionnaire as a covariate. The results showed that treatment by staff was the only experience with an impact on intention after screening $\left(r_{\text {part }}=0.19, \mathrm{n}=217\right.$, $\mathrm{p}<0.001)$. Similar analyses for the other cognitive determinants (except subjective norms) were performed. Results showed that pain during mammography had a significant influence on both self efficacy $\left(r_{\text {part }}=-0.19, \mathrm{n}=219\right.$, $\mathrm{p}=0.004)$ and on beliefs about the costs of screening $\left(r_{\text {part }}=0.40, \mathrm{n}=216, \mathrm{p}=0.004\right)$. Likewise, anxiety provoked by the mammography was correlated to self efficacy $\left(r_{\text {part }}=-0.27\right.$, $\mathrm{n}=219, \mathrm{p}<0.001)$ and costs $\left(r_{\text {part }}=0.33, \mathrm{n}=216\right.$, $\mathrm{p}<0.001$ ). All other (partial) correlations between experiences and cognitive determinants were not significant.

An additional multiple regression analysis, in which the cognitive determinants from table 8 (benefits, costs, susceptibility, severity, and self efficacy) were included to predict intention, showed that the cognitive determinants measured after screening significantly predicted the intention to reattend after screening $(R=0.41$, $F(6,479)=18.9, \mathrm{p}<0.001)$. Expectations of self efficacy $(\beta=0.42, p<0.001)$ and perceived susceptibility $(\beta=0.12, \mathrm{p}=0.005)$ were independent predictors of intention to reattend.

Table 7 Mean scores on cognitive determinants of repeat participation measured before the first and after the second questionnaire in the initial round of the breast cancer screening programme

\begin{tabular}{|c|c|c|c|c|c|c|}
\hline & \multicolumn{3}{|l|}{ Mean scores } & \multicolumn{3}{|l|}{ Test for effect } \\
\hline & $\begin{array}{l}\text { Before } \\
\text { mammography } \\
\text { (before+after } \\
\text { group) }\end{array}$ & $\begin{array}{l}\text { After } \\
\text { mammography } \\
\text { (before+after } \\
\text { group) }\end{array}$ & $\begin{array}{l}\text { After } \\
\text { mammography } \\
\text { (after only } \\
\text { group) }\end{array}$ & $\begin{array}{l}\text { Effect of } \\
\text { testing }\end{array}$ & $\begin{array}{l}\text { Effect of } \\
\text { screening } \\
\text { (between } \\
\text { subjects) } \dagger\end{array}$ & $\begin{array}{l}\text { Effect of } \\
\text { screening } \\
\text { (within } \\
\text { subjects) } \neq\end{array}$ \\
\hline Intention $(-2 / 2)$ & 1.8 & 1.8 & 1.8 & NS & NS & NS \\
\hline Benefits $(1 / 5)$ & 4.3 & 4.3 & 4.3 & NS & NS & NS \\
\hline Costs $(1 / 5)$ & 2.1 & 1.9 & 1.9 & NS & .01 & 0.001 \\
\hline Susceptibility (1/4) & 2.9 & 2.9 & 2.8 & NS & NS & NS \\
\hline Severity $(1 / 4)$ & 3.7 & 3.6 & 3.6 & NS & NS & NS \\
\hline Subjective norms $(-6 / 6)$ & 2.9 & 3.2 & 2.7 & 0.001 & NS & 0.010 \\
\hline \multirow[t]{2}{*}{ Self efficacy $(1 / 4)$} & 3.8 & 3.9 & 3.9 & NS & 0.00 & 0.003 \\
\hline & & & & $\begin{array}{l}F_{(7,469)}=3.5 \\
\mathrm{p}=0.001\end{array}$ & $\begin{array}{l}F_{(7,461)}=2.7 \\
\mathrm{p}=0.010\end{array}$ & $\begin{array}{l}F_{(7,188)}=5.7 \\
\mathrm{p}<0.001\end{array}$ \\
\hline
\end{tabular}

^MANOVA (between subjects design) was used to compare the scores after mammography of the before+after group with the after only group.

†MANOVA (between subjects design) was used to compare the scores after mammography of the after only group with the scores before mammography of the before+after group.

¥MANOVA (within subjects design for repeated measures) was used to compare the scores after mammography with the scores before mammography of the before+after group. 
Table 8 Correlations between experiences during first mammographyt and cognitive determinants of repeat participation, expressed after and before mammography

\begin{tabular}{|c|c|c|c|c|c|}
\hline & Travelling time & Waiting time & Treatment by staff & Pain & Anxiety \\
\hline \multicolumn{6}{|c|}{ Cognitive determinants expressed after the mammography: } \\
\hline Intention $(-2 / 2) \ddagger$ & - & $-0.13^{\star}$ & $0.22^{\star \star \star}$ & $-0.15^{\star \star \star}$ & - \\
\hline Benefits $(1 / 5) \ddagger$ & - & - & - & - & $0.12^{\star}$ \\
\hline Costs $(1 / 5) \ddagger$ & $0.13^{\star \star}$ & - & - & $0.43^{\star \star \star}$ & $0.53^{\star \star \star}$ \\
\hline Susceptibility $(1 / 4) \ddagger$ & $-0.11^{\star}$ & - & - & - & $0.16^{\star \star}$ \\
\hline Severity $(1 / 4) \ddagger$ & - & - & $0.13^{\star}$ & - & $0.14^{\star \star}$ \\
\hline Subjective norms $(-6 / 6)$ S & - & - & - & - & $0.22^{\star \star}$ \\
\hline Self efficacy $(1 / 4) \ddagger$ & $-0.11^{\star \star}$ & - & $0.11^{\star}$ & $-0.29^{\star \star}$ & $-0.52^{\star \star}$ \\
\hline \multicolumn{6}{|c|}{ Cognitive determinants expressed before the mammography: } \\
\hline Intention $(-2 / 2)$ & $-0.16^{\star}$ & - & - & - & - \\
\hline Benefits $(1 / 5)$ & - & $-0.15^{\star}$ & $-0.16^{\star}$ & - & $0.12^{\star}$ \\
\hline Costs $(1 / 5)$ & $0.19^{\star}$ & - & - & $0.14^{\star}$ & $0.41^{\star \star \star}$ \\
\hline Susceptibility $(1 / 4)$ & $-0.11^{\star}$ & - & - & - & $0.16^{\star}$ \\
\hline Severity $(1 / 4)$ & - & - & $-0.18^{\star \star}$ & - & $0.17^{\star \star}$ \\
\hline Subjective norms $(-6 / 6)$ & - & - & - & - & $0.19^{\star \star}$ \\
\hline Self efficacy $(1 / 4)$ & $-0.15^{\star \star}$ & - & - & - & $-0.48^{\star \star}$ \\
\hline
\end{tabular}

\section{Discussion}

The results of the study showed that women were generally very positive about their first breast examination. The screening unit was within easy reach for nearly everyone, women did not have to wait long for their turn, the (semimobile) screening unit offered enough privacy, and women tended to be satisfied about their treatment by the staff. For most women, the breast examination and waiting for the test results did not cause extreme anxiety. However, pain or discomfort was mentioned by many participants: for most women (47\%) the breast examination had been a little painful, $14 \%$ reported moderate to severe pain. These findings are consistent with various other studies which show generally high levels of satisfaction with screening (including respect for privacy and treatment by staff) but in which pain or discomfort is often mentioned. ${ }^{34-38}$

Various authors have suggested that screening might cause false reassurance. ${ }^{6-8}$ The results of our study provide no indications of false reassurance among women who received a negative screening result. Nearly all women knew that participating in the breast cancer screening programme does not mean that you cannot get breast cancer in the future. Likewise, nearly all women knew that having a mammogram does not make breast self examination superfluous. More than $99 \%$ of the women would consider the possibility of breast cancer if they discovered a lump in one of their breasts. If this occurred, most women intended to seek medical help within a week. Less than $4 \%$ would wait more than 1 month, less than $1 \%$ would wait longer than 2 months. These variables were not influenced by the experience of mammography with a benign result. Even when a woman was recently reassured by a negative mammogram, she realised that a lump might mean breast cancer and would seek medical help promptly. However, the results must be interpreted with some caution as the assessed intentions to seek help referred to a hypothetical situation and might not correspond with actual behaviour. In a retrospective study by Boer and Seydel, ${ }^{39}$ it was found that
$13 \%$ of patients with recently diagnosed breast cancer reported having postponed consulting a doctor for as long as possible (at least for more than several weeks after discovering the symptoms). The results from our study are much more optimistic: it can therefore be questioned whether the expressed intentions would correspond with actual behaviour. However, this study was primarily focused on detecting changes in opinions as a result of an experience of mammography. The results show that no such changes occurred after a negative mammography result. A second point to be made is that the women in the study had experienced only one screening examination. It is possible that if a woman were to receive many negative screening results, she would be falsely reassured in the long run. To examine this, a longitudinal design would be necessary.

One of the study's main aims was to examine the influence of an experience of mammography with normal, benign results on women's intentions to repeat participation. The results showed that in general women were very positive about repeat participation, both before and after screening. After screening, the average woman connected even fewer costs with participating (in particular the costs: makes me worry and takes a lot of time were less often mentioned after screening), and perceived her own ability to engage in future screening as higher. The observed changes might reflect an effect of the negative screening result or an effect of the actual experience of undergoing a mammography. The study design does not allow for conclusions to be drawn about the exact cause of the changes (the two factors cannot be separated). However, it is likely that the observed changes in perceived costs and self efficacy are caused by the experience of mammography, which was better than expected for most women. We thought that a negative screening result might influence a woman's ideas about her susceptibility to breast cancer. The results showed that no significant differences on susceptibility were found before and after screening. The intention to participate in subsequent screening rounds was very high at both measurements 
and was not affected by the initial screening experience. These results, especially the finding that participation in screening improved self efficacy and reduced considerations about the costs, suggest that efforts to improve first round participation should be continued.

In this study the effect of specific experiences, such as the duration of the travel times, the amount of pain and anxiety, and the degree of satisfaction about treatment by staff, on cognitive determinants, was also examined. One interesting finding was that some experiences (expressed after mammography) were significantly correlated with cognitive determinants expressed before the screening. This indicates that the screening experience is determined by previous expectations. Women who beforehand anticipated more costs to participating and less ability to participate, did indeed experience more distress and more pain during their initial breast examination. Women who (before screening) connected more benefits to the screening, reported (after screening) shorter waiting times and were more satisfied with the treatment by staff. This indicates that a positive attitude towards screening can affect the perception of what is actually happening during the initial breast examination. On the other hand, some negative experiences did result in less positive views about reparticipation. As women experienced more pain or more anxiety during the breast examination, their expectations of self efficacy decreased and they were more likely to change their beliefs about the costs associated with screening (but not their intentions to reparticipate in future screening rounds). A significant finding was that women who were less satisfied about treatment by staff were more likely to change their reparticipation intentions negatively. It is important to note that in the present study no actual repeat participation was measured. Future research has yet to show whether women's positive intentions were indeed transformed into repeat participations.

Finally it should be noticed that our study was carried out in a rural area. Previous research has shown that in organised breast screening, attendance rates tend to be higher in rural areas than in urban areas. ${ }^{23} 40$ This means that the results of this study may not be generalisable to the whole population.

PRACTICAL IMPLICATIONS

The results from this study suggest that efforts to improve first round participation must be continued, as in general women who can be convinced to participate once will become more positive about regular participation. The screening experience with negative results helps women to connect fewer costs with screening and makes them more comfortable about their own abilities to participate. Alongside this, the screening organisations must continue to prioritise maintaining a high level of client friendliness during the screening. Our study showed that most women strongly intended to reparticipate in future screening rounds, even if they reported negative experiences like pain or anxiety. For some women, however, negative experiences did influence thoughts about future participation. Women who were less satisfied about the way they were treated by staff changed their intentions to reparticipate in a negative way. Finally, the results of our study show that most women seem to be very aware of how to interpret a negative screening result. Nearly all women realised that the negative screening result is not an absolute protection against breast cancer, and most women did not change their intentions about consulting a GP immediately in the case of symptoms of breast cancer. This indicates that additional health education alongside a negative screening result does not seem necessary at the present time.

This study was financed by the Dutch Cancer Society.

1 Shapiro S, Venet W, Strax P, et al, eds. Current results of the breast cancer screening randomized trial: the health insurance plan (HIP) of greater New York study. Toronto: Hans Huber, 1988.

2 Tabar L, Fargerberg G, Duffy SW, et al. Update of the Swedish 2 county program of mammography screening for breast cancer. Radiol Clin North Am 1992;30:187-210.

3 Tabar L, Fagerberg G, Chen H, et al. Efficacy of breast cancer screening by age. Cancer 1995;75:2507-17.

4 Collette HJA, Waard de F, Rombach JJ, et al. Further evidence of benefits of a (non- randomised) breast cancer screening programme: the DOM project. $\mathcal{F}$ Epidemiol Community Health 1992;46:382-6

5 Verbeek ALM, Hendriks JHCL, Holland R, et al. Reduction of breast cancer mortality through mass screening with modern mammography: first results of the Nijmegen project. Lancet $1984 ; \mathrm{i}: 1222-4$

6 Hurley SF, Kaldor JM. The benefits and risks of mammographic screening for breast cancer. Epidemiol Rev 1992;14:101-30.

7 Dilhuydy MH, Barreau B. The debate over mass mammography: is it beneficial for women? Eur $\mathcal{F}$ Radiol 1997;24:86-93.

8 Harris R, Leininger L. Clinical strategies for breast cancer screening: weighing and using the evidence. Ann Intern Med 1995;122:539-47.

9 Dijck JAAM van, Verbeek ALM, Hendriks JHCL, et al. The current detectability of breast cancer in a mammographic screening program. Cancer 1993;72:1933-8.

10 Brekelmans CTM. Natural history and epidemiology of interval breast cancer in the DOM screening programme [thesis]. Utrecht, The Netherlands: Universiteit Utrecht, 1995.

11 Otten JDM, Dijck JAAM van, Peer PGM, et al. Long term breast cancer screening in Nijmegen, The Netherlands: the nine rounds from 1975-92. F Epidemiol Community Health 1996;50:353-8.

12 Thurfjell EL, Lindgren JAA. Population based mammography screening in Swedish clinical practice: prevalence and incidence in Uppsala County. Radiology 1994;193:351-7.

13 Smale P, Elwood JM, Bandaranayake M. Evaluation of the Otago Southland pilot breast screening programme: report on the second round of screening (1994-6). Dunedin: Hugh Adam Cancer Epidemiology Unit, 1997.

14 Lerman C, Rimer B, Trock B, et al. Factors associated with repeat adherance to breast cancer screening. Prev Med 1990;19:279-90.

15 Scaf-Klomp W, Sonderen E van, Heuvel W van den. Compliance after 17 years of breast cancer screening: factors associated with reattendance for periodic breast screening. Eur F Public Health 1997;7:182-7.

16 Lechner L, Vries H de, Offermans N. Participation in a breast cancer screening program: influence of past behavior and determinants of future screening participation. Prev Med 1997;26:473-82.

17 Elwood M, McNoe B, Smith T, et al. Once is enough: why some women do not continue to participate in a breast some women do not continue to participate in a breast
cancer screening programme. NZ Med f 1998;111:180-3. 8 Rutter DR. Attendance and reattendance for breast cancer screening: a prospective 3 year test of the theory of planned behaviour. British fournal of Health Psychology 2000;5:1-13.

19 Marshall GA. A comparative study of re-attenders and nonre-attenders for second triennial national breast cancer screening program appointments. F Public Health Med 1994;16:79-86.

20 Orton M, Fitzpatrick R, Fuller A, et al. Factors affecting women's response to an invitation to attend for a second breast cancer screening examination. Br f Gen Pract 1991; 41:320-3

21 Vernon, SW, Laville EA, Jackson GL. Participation in breast screening programs: a review. Soc Sci Med 1990;30:110718 .

22 Sutton S, Bickler G, Sancho Aldridge J, et al. Prospective study of predictors of attendance for breast screening in
inner London. $\mathcal{F}$ Epidemiol Community Health 1994;48:6573 . 
23 Aro AR, Koning HJ de, Absetz P, et al. Psychological predictors of first attendance for organised mammography screening. $\mathcal{F}$ Med Screen 1999;6:82-8.

24 Janz NK, Becker MH. The health belief model: a decade later. Health Education Quarterly 1984;11:1-47.

25 Ajzen I, Fischbein M. Understanding attitudes and predicting behavior. Englewood Cliffs, NJ: Prentice Hall, 1980.

26 Ajzen I. From intentions to actions: a theory of planned behavior. In: Kuhl J, Beckmann J, eds. Action control: from cognition to behavior. Berlin: Springer-Verlag, 1985:11-39.

27 Rogers RW. Cognitive and physiological processes in fear appeals and attitude change. A revised theory of protection motivation. In: Cacioppo JT, Petty RE, eds. Social psychophysiology: a source book. New York: The Guilford Press, 1983.

28 Maddux JE, Rogers RW. Protection motivation and self efficacy: a revised theory of fear appeals and attitude change. F Exp Soc Psychol 1983;19:469-79.

29 Rutledge DN, Hartmann WH, Oney Kinman P, et al. Exploration of factors affecting mammography behaviors. Prev Med 1988;17:412-22.

30 Irwig L, Cockburn J, Turnbull D, et al. Women's perceptions of screening mammography. Australian Fournal of Public Health $1991 ; 15: 24-32$.

31 Champion V. Relationship of age to mammography compliance. Cancer 1994;74:329-35.

32 Montano DE, Taplin SH. A test of an expanded theory of reasoned action to predict mammography participation. Soc Sci Med 1991;32:733-41.
33 Boer H, Seydel ER. Protection motivation theory. In: Connor $M$, Norman $P$, eds. Predicting health behaviour. Buckingham: Open University Press 1995:95-120.

34 Seow A, Straughan PT, Ng EH, et al. Population based mammographic screening in Singapore: what are participants views? Ann Acad Med Singapore 1998;27:154-60.

35 Bakker DA, Lightfood NE, Steggles S, et al. The experience and satisfaction of women attending breast cancer screening. Oncology Nurs Forum 1998;25:115-21.

36 Vaile MSB, Calnan M, Rutter DR, et al. Breast cancer screening services in three areas: uptake and satisfaction. $\mathcal{F}$ Public Health Med 1993;15:37-45.

37 Aro AR, Absetz-Ylostalo P, Eerola T, et al. Pain and discomfort during mammography. Eur F Cancer 1996;32: $1674-9$.

38 Rutter DR, Calnan M, Vaile MSB, et al. Discomfort and pain during mammography: description, prediction, and prevention. BMF 1992;305:443-4

39 Boer H, Seydel ER. Van klacht tot diagnose: Uitstelgedrag van patiënt en huisarts bij symptomen van kanker (from complaint to diagnosis: patient's and doctor's delay in case of cancer symptoms). Tijdschrift Sociale Gezondheidszorg $1994 ; 72: 248-52$

40 Fracheboud J, Koning $\mathrm{H}$ de, Beemsterboer PMM, et al. Nation wide breast cancer screening in The Netherlands: results of initial and subsequent screening 1990-5. Int $\mathcal{F}$ Cancer 1998;75:694-8.

\section{Acknowledgements}

Professor Wald would like to thank the following who have generously given their time to help with the assessment of manuscripts during 2001, and particularly those who have collaborated on the screening briefs.

\section{Referees}

Professor Eva Alberman

Ms Alison Amos

Dr Bruce Armstrong

Dr A Aro

Professor Deborah Ashby

Dr Wendy Atkin

Dr Joan Austoker

Dr Anne-Marie

Benhamiche-Bouvier

Professor Tim Bishop

Dr Roger Blanks

Dr Rob Boer

Dr Jack Canick

Professor Howard Cuckle

Professor Jack Cuzick

Professor Nick Day

Professor Michael de Sweit

Dr Carol Dezateaux
Professor John Dickinson

Mrs Elizabeth Dormandy

Dr Constance Drossaert

Dr James D Goldberg

Mr Allan Hackshaw

Dr James Haddow

Professor Matti Hakama

Dr Amanda Herbert

Dr Basil Hetzel

Mr Wayne Huttly

Professor R J Jarrett

Professor Henry Kitchener

Professor Barnett Kramer

Professor Malcolm Law

Dr John Lazarus

Mr Ian Leck

Professor James Leonard

Professor Bernard Levin
Dr Harvey Levy

Professor Theresa Marteau

Dr Jenny McCann

Dr Mike Michell

Professor J Monson

Dr Joan Morris

Dr Sue Moss

Dr Jean Mulligan

Dr S Muttukrishna

Dr I Ostman-Smith

Mr Ian O'Sullivan

Mr Glenn Palomaki

Mr Simon Rish

Professor Charles Rodeck

Mr Patrick Royston

Dr Alicja Rudnicka

Dr Peter Sasieni

Professor J Scholefield
Dr Victoria Senior

Mr Adrian Stephens

Dr Y Syndercombe-Court

Dr Laszlo Tabar

Mr Anthony Threlfall

Mrs Chris Tinkler

Dr Lyndal Trevena

Dr Peter Twining

Dr Carla van Gils

Dr Gerrit van Oortmarssen

Mrs Jan Warner

Dr Ruth Warren

Dr David Wald

Dr Matthew Wallis

Professor U Wendel

Dr Bridget Wilcken

Dr Kenneth Young

\section{Screening brief collaborators}

\author{
Dr John Bamford \\ Dr Robert Clarke \\ Professor Howard Cuckle \\ Professor Adrian Davies \\ Dr Mike Gill
}

Dr Joan Morris

Mr Glenn Palomaki

Professor Catherine Peckham

Professor David Porteous

Professor John Scott
Dr David Wald

Dr Bridget Wilcken 